\title{
Influence of indoor air quality and personal factors on the sick building syndrome (SBS) in Swedish geriatric hospitals
}

\author{
Klas Nordström, Dan Norbäck, Roland Akselsson
}

\begin{abstract}
Objectives-Sick building syndrome (SBS) involves symptoms such as irritation to the eyes, skin, and upper airways, headache, and fatigue. The relations between such symptoms and both personal and environmental factors were studied in 225 female hospital workers, working in eight hospital units in the south of Sweden.
\end{abstract}

Methods-Symptoms of SBS and personal factors were measured by means of a standardised self administered questionnaire. The technical investigation comprised a building survey and measurements of room temperature, supply air temperature, air humidity, and exhaust air flow.

Results-The prevalence of symptoms differed from one unit to another. The mean value of weekly complaints of fatigue was $30 \%$, of eye irritation $23 \%$, and of dry facial skin 34\%. Eye irritation was related to work stress, self reported exposure to static electricity, and was also more common in buildings with a high ventilation flow and a high noise level (55 dB(A)) from the ventilation system. Nasal symptoms were related to asthma and hay fever only. Throat symptoms were more common in smokers, subjects with asthma or hay fever, new buildings, and in buildings with a high ventilation flow. Facial skin irritation was related to a lack of control of the work conditions, and was more common in new buildings, and buildings with a high ventilation flow and ventilation noise. General symptoms, such as headache and fatigue, were related to current smoking, asthma or hay fever, work dissatisfaction, and static electricity.

Conclusion-As the prevalence of symptoms was high, there is a need to improve the indoor environment as well as the psychosocial environment in hospitals. These improvements could include a reduction of ventilation noise, minimised smoking, and improvements in the psychosocial climate. Further research is needed to identify indoor climatic factors that cause the increased prevalence of symptoms of SBS in new buildings.

(Occup Environ Med 1995;52:170-176)

Keywords: building age; mechanical ventilation; room temperature; sick building syndrome; static electricity
The so called sick building syndrome (SBS) comprises various non-specific symptoms such as eye, skin, and upper airway irritation, headache, and fatigue. ${ }^{1-8}$ In recent years, several epidemiological investigations of such symptoms have been published. ${ }^{2-7}$ Various factors such as the age of the building, ${ }^{5}$ type of ventilation system, ${ }^{6}$ room temperature, ${ }^{7}$ static electricity, ${ }^{3}$ and volatile organic compounds ${ }^{8}$ have been shown to be related to the occurrence of symptoms of SBS. Most of the research on SBS has been performed in office workers. A large proportion $(17 \%)$ of the female workforce in Sweden are employed in the medical services. ${ }^{9}$ As many aspects of the working conditions, and indoor environments, may differ between hospitals and offices, it is not clear whether knowledge gathered from the large office studies ${ }^{245}$ is valid also in the hospital environment. There are, however, indications that symptoms of SBS are also common in the medical services, ${ }^{3} 1011$ but little information is available on relations between symptoms and indoor climate in hospitals. To provide further insights into the effects of the hospital environment on health, we started several field studies in hospitals. These studies are focused on the perception of air quality, on symptoms of SBS, and on the health effects of air humidification.

The first aim of this investigation was to study the relation between symptoms of SBS and measured physical environment in hospitals. The second aim was to examine the influence of personal factors on such symptoms.

The following hypotheses about the indoor environment were tested: the prevalence of symptoms of SBS is related to high room temperature, low outdoor air flow, building dampness in concrete slabs, plastic floor coatings, exposure to static electricity, environmental tobacco smoke, noise from the ventilation system, and building age. For personal factors, the following hypotheses were tested: symptoms of SBS in hospital employees are related to age, employment duration, asthma symptoms, hay fever, tobacco smoking, psychosocial factors, and the physical workload.

Subjects and methods

SUBJECTS

The study was performed in three municipalities in the county of Malmöhus in southern Sweden, all belonging to the same hospital district. In patient medical services in this 
district comprised nine public geriatric hospital units and one public hospital for non-geriatric patients. Also, there were a few privately run geriatric hospital units in the district. To increase the homogeneity of the population, the study was restricted to staff working in the public geriatric hospital units. One of the units had recently participated in a pilot questionnaire study and was therefore excluded from this investigation. All personnel in the other eight units $(n=287)$ were included in the study population. The study base was the study population observed during a three month period (December 1988-February 1989).

\section{ASSESSMENT OF SYMPTOMS}

The occurrence of symptoms was registered by means of a standardised self administered questionnaire. The questionnaire has been used in Sweden for some years, and most of the questions have been validated previously. The current version, with the designation MM040B, was developed by the Department of Occupational Health in Örebro, Sweden, ${ }^{12}$ and has been used in the large office illness study in northern Sweden. ${ }^{4}$ It contains questions on perceived air quality; symptoms included in the sick building syndrome; personal factors; and the psychosocial climate at the workplace. A recall period of three months was used in the questionnaire. Fifteen questions on medical symptoms were included in the questionnaire. Two of the questions dealing with dermal symptoms of the hands or scalp were excluded from the analysis because such symptoms are not included in the definition of SBS. ${ }^{14}$ The remaining 13 questions were; one question on eye irritation, one on nasal symptoms, three on throat symptoms, three on facial dermal symptoms, and five on general symptoms. For each symptom, an answer could be given according to one of three options; "no never", "yes sometimes", and "yes often"-often meaning every week. Symptoms related to work were not assessed in the questionnaire. There was one question asking whether the respondents attributed the symptoms to indoor climatic factors. This information, however, was not used in this study, which covered symptoms regardless of the subjects' opinions on causes.

The questionnaire was distributed to all hospital employees at the workplaces in February 1989, and was answered within two weeks. The prevalence of weekly symptoms was calculated for each symptom. In the logistic regression analysis, symptoms were grouped into five categories: eye symptoms, nasal symptoms, throat symptoms, facial dermal symptoms, and general symptoms. In each category, subjects with at least one weekly symptom were assigned the value 1, and subjects with no weekly symptom in the category were assigned 0 . In the linear regression analysis, an overall score for symptoms of SBS ranging from 0 to 26 was constructed, by summing up the individual symptom scores. Here, each of the 13 symptoms was scored from $0-2$; weekly complaints were assigned value 2 , yes sometimes were assigned value 1 , and no never were assigned a value 0 .

\section{ASSESSMENT OF PERSONAL FACTORS}

Information on age, sex, number of working hours, degree of heavy physical workload, smoking habits, hay fever, and asthmatic symptoms was obtained from the questionnaire. The current version of the questionnaire contained three questions that covered different aspects of the psychosocial work conditions. The question involving "interesting or stimulating work" measured work satisfaction. The question "too much work to do" covered work stress, and the "opportunity to influence working conditions" measured the degree of personal influence experienced by the subjects. The questions on psychosocial conditions, and degree of work load, had four possible answers: "yes often", "yes sometimes", "no seldom", and "no never". Each of the variables was assigned an index value, 3, 2 , 1 , or 0 respectively, according to the answer. Also, a psychosocial dissatisfaction index was calculated by forming a total sum of the three indices $(0-12)$.

\section{ASSESSMENT OF EXPOSURE}

The technical investigation comprised a building survey and measurements of temperature, air humidity, and exhaust air flow rate per person. The investigation was performed by an experienced safety engineer. In the building survey, information was gathered on the age of the building, the type of ventilation system, type of floor covering, signs of building dampness, and smoking restrictions in the building. Both the inspection, and the indoor measurements, were performed from January to March 1989, in close time connection with the questionnaire study. No information on the result of the technical measurements was delivered to the hospital units before the questionnaire study was completed.

Temperature was measured with a four channel instrument (MITEC MTM 20). The temperature was registered every hour during the daytime on seven consecutive days in each unit, and recorded in a datalogger. The sites of measurement were outdoor air, supply air, and locations in two different rooms. Parallel measurements of room temperature and relative air humidity were performed in another room by a thermohygrograph (CASELLA $T$ 9420). Exhaust air flows were measured in each hospital room by a thermoanemometer (ALNOR GGA 65 P). Momentary noise level was recorded by a noise meter (Bruel and Kjaer 2203) with an octave filter 1613. All measuring instruments were calibrated. The thermoanemometer was calibrated by the Swedish National Institute of Building Research before measurements were taken. The four channel temperature instrument was calibrated before and during the measuring period by comparison with an accurate mercury thermometer. The thermohygrograph was calibrated by comparison with a sling psychrometer.

For each hospital unit, the following mean 
variables were calculated: the mean exhaust air flow was calculated from the arithmetic mean value of all hospital room measurements. The mean exhaust air exchange flow per person was calculated by dividing the mean exhaust air flow by the number of subjects in the room. The mean room temperature, supply air temperature and relative air humidity in the rooms were calculated for each hospital unit. The temperature difference was defined as the difference between the highest and lowest temperature recorded in each hospital unit during the investigation period.

\section{STATISTICAL METHODS}

Relations between different exposure variables were analysed by means of linear regression analysis. The influence of different factors on the different symptoms was analysed by way of multiple logistic regression, by SPIDA statistical package (The Statistical Laboratory, Macquaire University, Australia). The collinearity diagnostics described in the SPIDA manual were applied. ${ }^{13}$ The statistical analysis was performed in five steps. Firstly, all personal factors were forced into the model. Secondly, all significant personal factors were maintained in the model. As a third step, measured exposure variables were forced into the model one by one. The fourth step entailed the maintenance of all significant exposure variables in the model, unless collinearity problems were detected. Finally, all non-significant variables were excluded. Throughout the statistical analysis, two tailed tests and a 5\% level of significance were used.

\section{Results}

PERSONAL CHARACTERISTICS

The overall response rate was $82 \%$. The median employment time was three years, and $40 \%$ of the workers had worked one year or less at the current workplace. In total, 225 of the responders were women, and 10 were men. The mean age was 37 years among the women responders, and 34 years in the men. The prevalence of current smokers was $45 \%$ among women, and $20 \%$ among men. The physical workload was perceived as often

Table 1 Three month prevalence of weekly complaints of SBS symptoms in all the hospital employees $(n=235)$

\begin{tabular}{llll}
\hline & \multicolumn{2}{c}{ Prevalence (\%) } & \\
\cline { 2 - 4 } Variable & $\begin{array}{l}\text { Women } \\
(n=225)\end{array}$ & $\begin{array}{l}\text { Men } \\
(n=10)\end{array}$ & Range (\%)* \\
\hline Fatigue & 30 & 20 & $21-43$ \\
Feeling heavy headed & 22 & 20 & $11-35$ \\
Headache & 20 & 0 & $13-32$ \\
Nausea or dizziness & 2 & 0 & $0-4$ \\
Difficulties concentrating & 1 & 0 & $1-4$ \\
Itching, burning, or irritated eyes & 23 & 0 & $7-41$ \\
Irritated, stuffy, or runny nose & 15 & 0 & $9-21$ \\
Hoarse, dry throat & 28 & 0 & $18-39$ \\
Throat pain & 2 & 0 & $0-5$ \\
Cough & 4 & 0 & $0-7$ \\
Dry facial skin & 34 & 0 & $4-55$ \\
Flushed facial skin & 8 & 0 & $0-15$ \\
Itchy, stinging, tight or & & & $3-13$ \\
burning sensation in facial skin & 8 & 0 & \\
\hline * Range of prevalence in each hospital unit. & & &
\end{tabular}

being heavy by most workers $(69 \%$ of the women and $70 \%$ of the men). Hay fever occurred in similar proportions in both women and men (11\% and $10 \%$ respectively), and asthma was reported by $9 \%$ of the women, and $10 \%$ of the men. Self reported asthma was strongly related to hay fever $(\mathbf{P}<$ 0.01 , and was grouped together in the statistical analysis.

\section{OCCURRENCE OF SYMPTOMS}

The hospital employees often complained of general symptoms, mucosal irritation, and skin symptoms. Weekly complaints of fatigue were reported by $30 \% ; 19 \%$ reported headache; $28 \%$ reported a dry throat; and $33 \%$ reported facial dryness. There were, however, large variations between buildings with regard to the occurrence of symptoms (table 1). Eighty two subjects reported that their symptoms were independent of the season, 46 subjects reported that the symptoms were most prevalent during the winter; and only two people reported that their symptoms were most common in spring. Forty four of the women (20\%) reported that they had been to a physician because of the symptoms. Due to the small number of men, all statistical analyses were restricted to the 225 women employees.

\section{BUILDING CHARACTERISTICS}

All hospital units were in small towns (5000-25 000 inhabitants), not near heavy traffic, or polluting industries. All buildings were built of concrete or bricks, with slanting tile roofs, and all had openable windows. Fibreglass or rockwool were not present openly within the rooms of any building. No use of video display units (VDU) was found in any of the units. The four newest units had sun protection devices above the windows, to minimise temperature differences in the room. Three of the units had signs of dampness in the concrete floor slab, which was verified by humidity measurements. The floor coatings consisted of either linoleum or polyvinylchloride (PVC) material, and no wall to wall carpets were found. All buildings were equipped with mechanical ventilation with both supply and exhaust air (mixed system), without air humidification or air cooling devices. Also, all ventilation systems were equipped with rotary air to air heat exchangers without any return air device. The heating system was always water borne central heating, in combination with air heating by way of the supply air. None of the ventilation systems had been cleaned, and the inlet filter type was F 45. General smoking indoors was allowed in two units and restricted to certain rooms in the other six units. The cleaning procedures included daily mopping with water. No use of glutaraldehyde or other biocides, either as cleaning materials or in the ventilation systems, occurred. Bulk dispensing of Isphagula prepared from dried leaflets or pods from senna were not done in any unit, and the degree of use of latex gloves was similar in all units. 
Table 2 Mean (range) of measured physical factors and building age of eight hospital units

\begin{tabular}{ll}
\hline Variable & Arithmetic mean (range) \\
\hline Room temperature $\left({ }^{\circ} \mathrm{C}\right)^{\star}$ & $22 \cdot 6(22 \cdot 0-24 \cdot 0)$ \\
Room temperature difference $\left({ }^{\circ} \mathrm{C}\right) \dagger$ & $2 \cdot 1(1 \cdot 0-3 \cdot 0)$ \\
Supply air temperature $\left({ }^{\circ} \mathrm{C}\right)^{\star}$ & $22 \cdot 2(20 \cdot 0-25 \cdot 0)$ \\
Exhaust air flow $(1 / \mathrm{s}$. person) & $5 \cdot 3(0 \cdot 6-17 \cdot 2)$ \\
Building age $(\mathrm{y})$ & $38(2-76)$
\end{tabular}

*Mean (range) for the eight units; tmean (range) of the difference between lowest and highest value during one week.

Table 3 Prevalence of various exposure conditions among female employees $(n=225)$ in eight hospital units

\begin{tabular}{ll}
\hline Type of exposure & $\begin{array}{l}\text { Prevalence of } \\
\text { exposure (\%) }\end{array}$ \\
\hline Plastic PVC floor coating & 76 \\
Building dampness in concrete slab & 41 \\
Exhaust air flow below current standard† & 87 \\
General smoking permitted indoors & 24 \\
Room temperature above $22^{\circ} \mathrm{C}$ & 87 \\
Supply air temperature above $22^{\circ} \mathrm{C}$ & 52 \\
Working in a new building & 48 \\
(built after 1975) & 48
\end{tabular}

*All damp buildings had PVC floor coatings; tpersonal outdoor air flow rate $<8 \mathrm{l} / \mathrm{s}$.

\section{EXPOSURE CONDITIONS}

The outdoor temperature varied from +2 to $+8^{\circ} \mathrm{C}$, and the indoor relative humidity ranged between 25 and $40 \% \mathrm{RH}$. The average indoor temperature during the daytime was $22.6^{\circ} \mathrm{C}$ (table 2 ). The newest buildings had the lowest average room temperature as well as the lowest temperature difference. The average supply air temperature was $22 \cdot 2^{\circ} \mathrm{C}$. Table 2 shows that there were large variations in the exhaust air rates between different buildings. In a few rooms, no exhaust air flow could be registered due to imbalance in the ventilation system. The average exhaust air flow rate per person varied from 0.6 to $17 \cdot 2$ $1 / \mathrm{s}$ between different hospital units.

Relations between different exposure variables were analysed by means of linear regression analysis. A significant positive relation was found between supply air temperature and room temperature $(P<0.01)$. Also, a high supply air temperature was related to an increased variation in room temperature $(P<$ $0.05)$. There was also a relation between building age and exhaust air flow, the ventilation rate reaching the highest levels in new buildings $(P<0.05)$. Self reported exposure to static electricity was significantly related to building age, and was more common in new buildings $(P<0.05)$. No significant difference between linoleum floors, and plastic floor coating, with regard to reports on static electricity was detected.

Three quarters of the subjects worked in buildings with plastic PVC floors, and $41 \%$ worked in buildings with PVC floors in combination with dampness in the concrete slab. Only a minority (13\%) worked in buildings with personal outdoor air flow above the current standard of $81 / \mathrm{s},{ }^{14}$ and room temperature above the recommended maximum value of $22^{\circ} \mathrm{C}^{7}$ (table 3 ). In total, $35 \%$ reported weekly discomfort from static electricity, which often occurred when making beds for the patients. During the building inspection, unusual noise from the ventilation system was noted in one hospital unit. This exposure was verified by noise measurements that showed a noise level of $55 \mathrm{~dB}(\mathrm{~A})$, exceeding the recommended value of $40 \mathrm{~dB}(\mathrm{~A}) .^{15}$ Additional frequency analysis showed that the highest noise level was $58 \mathrm{~dB}(\mathrm{~A})$ at $31.5 \mathrm{~Hz}$.

\section{RELATIONS BETWEEN SYMPTOMS OF SBS AND} PERSONAL FACTORS

Because of the low proportion of men in the hospitals, the study on relations between symptoms, personal factors, and the indoor environment was restricted to the 225 female respondents (table 4). Eye symptoms were more common in subjects who reported a high degree of work stress. Nasal symptoms were related to asthma or hay fever only. Throat symptoms were more common in smokers, and in subjects with asthma or hay fever. Subjects who reported a low degree of control over the working conditions reported more facial dermal symptoms. Finally, general symptoms, such as fatigue and headache, were related to current smoking, asthma or hay fever, and dissatisfaction with the working conditions. No significant relations were found between age, duration of employment, degree of physical workload, and any type of symptoms.

\section{RELATIONS BETWEEN SYMPTOMS OF SBS AND EXPOSURE FACTORS}

Weekly reports on static electricity were reported by $35 \%$ of the female employees, often in relation to making beds, and was

Table 4 Adjusted odds ratios (ORs) * with 95\% confidence interval (95\% CI) for relations between different types of symptoms, and personal factors in female hospital workers $(n=225)$

\begin{tabular}{|c|c|c|c|c|c|}
\hline \multirow[b]{2}{*}{ Type of factor } & \multicolumn{5}{|l|}{ Type of symptom } \\
\hline & $\begin{array}{l}\text { Eye† } \\
\text { OR }(95 \% \text { CI) }\end{array}$ & $\begin{array}{l}\text { Nasal } \ddagger \\
\text { OR }(95 \% C I)\end{array}$ & $\begin{array}{l}\text { Throat } \$ \\
\text { OR }(95 \% \text { CI })\end{array}$ & $\begin{array}{l}\text { Facial dermal } \\
\text { OR }(95 \% C I)\end{array}$ & $\begin{array}{l}\text { General } \\
\text { OR }(95 \% \text { CI })\end{array}$ \\
\hline $\begin{array}{l}\text { Current smoker }{ }^{\star \star} \\
\text { Asthma or hayfever }{ }^{\star \star} \\
\text { Work dissatisfaction }+\dagger \\
\text { Work stresst† } \\
\text { Lack of influence } \\
\end{array}$ & $\begin{array}{c}1 \cdot 1(0 \cdot 6-2 \cdot 2) \\
1 \cdot 4(0 \cdot 6-3 \cdot 4) \\
0 \cdot 4(0 \cdot 1-2 \cdot 7) \\
15 \cdot 7(2 \cdot 0-121) \\
1 \cdot 3(0 \cdot 3-5 \cdot 6)\end{array}$ & $\begin{array}{l}1 \cdot 5(0 \cdot 6-3 \cdot 5) \\
6 \cdot 7(3 \cdot 0-16) \\
2 \cdot 2(0 \cdot 2-21) \\
6 \cdot 0(0 \cdot 5-74) \\
3 \cdot 0(0 \cdot 4-20)\end{array}$ & $\begin{array}{l}2 \cdot 4(1 \cdot 2-4 \cdot 4) \\
2 \cdot 4(1 \cdot 1-5 \cdot 3) \\
0 \cdot 8(0 \cdot 2-4 \cdot 2) \\
1 \cdot 0(0 \cdot 1-7 \cdot 3) \\
2 \cdot 5(0 \cdot 6-10 \cdot 2)\end{array}$ & $\begin{array}{l}1 \cdot 4(0 \cdot 8-2 \cdot 4) \\
1 \cdot 4(0 \cdot 6-2 \cdot 9) \\
1 \cdot 3(0 \cdot 3-5 \cdot 2) \\
1 \cdot 7(0 \cdot 3-10 \cdot 3) \\
3 \cdot 5(1 \cdot 1-11 \cdot 6)\end{array}$ & $\begin{array}{l}2 \cdot 1(1 \cdot 1-3 \cdot 7) \\
4 \cdot 3(1 \cdot 9-9 \cdot 8) \\
4 \cdot 8(1 \cdot 1-21 \cdot 9) \\
4 \cdot 5(0 \cdot 7-31 \cdot 2) \\
1 \cdot 5(0 \cdot 4-5 \cdot 7)\end{array}$ \\
\hline
\end{tabular}

Lack of influence tf

*Adjusted for other significant personal factors, by multiple logistic regression; fitching, burning, or irritating eyes; firritated, stuffy runny nose; Shoarse or dry throat, throat pain, or irritating cough; ๆdry facial skin, flushed facial skin, or itchy, stinging, tight or burning sensation in facial skin; ||fatigue, feeling heavy headed, headache, difficulties concentrating, nausea or dizziness; were found between age, years of employment, degree of work load, and any type of symptoms. 
Table 5 Adjusted odds ratios (ORs) ${ }^{*}$ with 95\% CI for relations between different types of symptoms, and significant building characteristic and exposures

\begin{tabular}{|c|c|c|c|c|c|}
\hline \multirow[b]{2}{*}{ Type of exposure } & \multicolumn{5}{|l|}{ Type of symptom } \\
\hline & $\begin{array}{l}\text { Eye } \dagger \\
\text { OR }(95 \% \text { CI) }\end{array}$ & $\begin{array}{l}\text { Nasal } \\
\text { OR }(95 \% \text { CI) }\end{array}$ & $\begin{array}{l}\text { Throat } \\
\text { OR }(95 \% \text { CI) }\end{array}$ & $\begin{array}{l}\text { Facial dermal } \\
\text { OR }(95 \% \text { CI })\end{array}$ & $\begin{array}{l}\text { General } \| \\
\text { OR }(95 \% \text { CI })\end{array}$ \\
\hline $\begin{array}{l}\text { Exhaust air flow }{ }^{\star \star} \\
\text { New buildingtt } \\
\text { Ventilation noise } t \dagger \neq \ddagger \\
\text { Static electricity }+t \\
\text { (weekly perception) }\end{array}$ & $\begin{array}{l}2 \cdot 6(1 \cdot 4-5 \cdot 4) \\
1 \cdot 5(0 \cdot 8-2 \cdot 8) \\
4 \cdot 2(1 \cdot 7-10 \cdot 2) \\
2 \cdot 5(1 \cdot 2-4 \cdot 9)\end{array}$ & $\begin{array}{l}1.4(0.7-3.4) \\
2.0(0.9-4.6) \\
1.6(0.5-5.0) \\
0.9(0.4-2 \cdot 1)\end{array}$ & $\begin{array}{l}1.9(1.0-3.4) \\
2.0(1.1-3.8) \\
1.9(0.8-4.4) \\
1.6(0.8-3.0)\end{array}$ & $\begin{array}{l}1.9(1 \cdot 1-3 \cdot 4) \\
1.8(1.04-3 \cdot 3) \\
2 \cdot 3(1.03-5 \cdot 3) \\
1.6(0.9-2 \cdot 8)\end{array}$ & $\begin{array}{l}1.0(0.7-1 \cdot 9) \\
0.9(0.5-1 \cdot 6) \\
1.3(0.5-3 \cdot 1) \\
1.9(1.1-3.6)\end{array}$ \\
\hline
\end{tabular}

Footnotes as for table 4 except; $\star \star$ odds ratio calculated for a change of outdoor air flow of $101 / \mathrm{s}$ and person; $+\nmid 0=$ absence; $1=$ presence; ¥the newest building, and the only building with a personal outdoor air above current standard of $8 \mathrm{l} / \mathrm{s}$. Note: no signif icant relations were found between any type of symptoms and the following exposure variables: room temperature, supply air temperature, temperature difference, PVC floor coating, building dampness, and degree of environmental tobacco smoke.

related to both eye symptoms and general symptoms (table 5). Also, throat and facial dermal symptoms were more common in new buildings. In buildings built after 1975, the prevalence of dry facial skin was $43 \%$, compared with a $23 \%$ prevalence in older buildings. Facial dermal symptoms were also related to the exhaust air flow, and dermal symptoms, eye irritation, and throat symptoms were most prevalent in well ventilated buildings (table 5 ). The relation between symptoms and ventilation flow was significant even if subjects with asthma or hay fever were excluded from the analysis. Furthermore, no significant relations between symptoms and building age or ventilation flow was found among subjects with asthma or hay fever. The newest building was built in 1987, and was the only unit where the average outdoor air flow exceeded the current standard of 8 1/s/person. ${ }^{14}$ This building had increased noise levels due to noise from the ventilation system, and had a significantly increased prevalence of both eye symptoms and facial dermal symptoms (table 5). No effect of building dampness, type of floor coating, or general tobacco smoking indoors on the prevalence of symptoms of SBS could be detected. Furthermore, no significant influence of room temperature, supply air temperature, or temperature difference on any type of symptoms was found in the logistic regression analysis (table 5). Room temperature may be an aetiological factor at either extreme of the normal environmental range. To detect a $U$ shaped exposure-response relation, the prevalence of symptoms was stratified $v$ average room temperature (table 6). A significant $U$ shaped relation was found for throat symptoms $(\mathrm{P}<$ $0.05)$ and facial dermal symptoms $(P<0.01)$, to the extent that prevalence of symptoms in buildings with extreme temperatures (either

Table 6 Prevalence of different types of symptoms (\%) in female hospital workers, at different mean room temperatures $(n=225)$

\begin{tabular}{|c|c|c|c|c|c|c|}
\hline \multirow[b]{2}{*}{$\begin{array}{l}\text { Mean room } \\
\text { temperature }\end{array}$} & \multirow[b]{2}{*}{$n$} & \multicolumn{5}{|c|}{ Type of symptom } \\
\hline & & $\begin{array}{l}\text { Eye† } \\
(\%)\end{array}$ & $\begin{array}{l}\text { Nasal } \\
(\%)\end{array}$ & $\begin{array}{l}\text { Throat } \$ \\
(\%)\end{array}$ & $\begin{array}{l}\text { Facial dermal } \\
(\%)\end{array}$ & $\begin{array}{l}\text { General } \| \\
(\%)\end{array}$ \\
\hline $\begin{array}{l}22 \cdot 0 \\
22 \cdot 5 \\
23 \cdot 0 \\
23 \cdot 5 \\
24 \cdot 0\end{array}$ & $\begin{array}{l}28 \\
81 \\
58 \\
31 \\
27\end{array}$ & $\begin{array}{l}43 \\
19 \\
28 \\
13 \\
15\end{array}$ & $\begin{array}{l}18 \\
14 \\
13 \\
14 \\
22\end{array}$ & $\begin{array}{l}39 \\
24 \\
27 \\
24 \\
42\end{array}$ & $\begin{array}{l}57 \\
28 \\
37 \\
36 \\
52\end{array}$ & $\begin{array}{l}41 \\
44 \\
44 \\
47 \\
30\end{array}$ \\
\hline
\end{tabular}

Footnotes as for table 4 $22.0^{\circ} \mathrm{C}$ or $24.0^{\circ} \mathrm{C}$ ) was significantly higher than the prevalence in buildings with a mean room temperature in the range of $22.5^{\circ} \mathrm{C}$ to $23 \cdot 5^{\circ} \mathrm{C}$ ).

Finally, relations between the overall symptom score, personal factors, and exposures related to buildings were analysed. Similar results as for the logistic regression analysis were obtained. In the crude, bivariate analysis, the overall symptom score was related to psychosocial symptom score $(P<0.001)$, asthma or hayfever $(P<0.001)$, static electricity $(P<0.05)$, and noise from the ventilation system $(P<0.05)$. In the multiple linear regression analysis, the symptom score was significantly related to the psychosocial dissatisfaction score, asthma or hay fever, a high ventilation flow $(P<0.05)$, and reports on static electricity (table 7 ).

\section{Discussion}

Our results suggest that a large proportion of hospital employees in Sweden may have symptoms compatible with the sick building syndrome. A cross sectional study has certain drawbacks due to selection processes, and the number of available employees, which may limit the validity of the study. The most obvious drawback is a possible underestimation of the true effect because people with

Table 7 Multiple linear regression analysis of overall symptom score (0-26) in 225 female hospital employees, as a function of two significant personal factors and two significant exposure indicators $(P<0.05,95 \% C I=95 \%$ CI of regression coefficient)

\begin{tabular}{lc}
\hline Variable & $\begin{array}{l}\text { Linear model } \\
\text { Coefficient }(95 \% \mathrm{CI})\end{array}$ \\
\hline Asthma or hayfevert & $3 \cdot 3(1 \cdot 9-4 \cdot 7)^{\star \star \star}$ \\
Psychosocial dissatisfaction index & $12 \cdot 8(7 \cdot 4-18 \cdot 2)^{\star \star \star}$ \\
Exhaust ventilation flows & $0 \cdot 1(0 \cdot 01-0 \cdot 9)^{\star}$ \\
Perception of static electricityl & $1 \cdot 6(0 \cdot 2-3 \cdot 0)^{\star}$ \\
Constant & $2 \cdot 5$ \\
\hline
\end{tabular}

$\star P<0.05$, two tailed; $\star \star \star P<<0.001$, two tailed; $+0=$ absence 1 = presence; $\neq$ coefficient with $95 \% \mathrm{CI}$ calculated for extremes of the variable, ranging from 0 to 12 ; §coefficient with $95 \% \mathrm{CI}$ calculated for an increase of personal outdoor air flow of $10 \mathrm{l} / \mathrm{s}$ Icoefficient with $95 \%$ CI calculated for extremes of the variable, ranging from 0 to 2 . The following personal factors were not significant $(P>0.05)$ predictors of overall symptom were nom score: age, current tobacco smoking, employment time, and degree of heavy workload. The following exposure factors were not significant $(P>0.05)$ predictors of overall symptom score: room temperature, temperature difference, supply air temperature, degree of environmental tobacco smoke, building dampness, ventilation noise, building age, and presence of plastic
PVC floor coating. 
pronounced symptoms may leave a poor environment - that is, the possibility of a health based selection of employees. Such selection has mainly been associated with industrial exposures, but it may occur in non-industrial indoor environments, too. Despite these limitations, we showed significant relations between symptoms and both personal factors and exposures related to buildings.

A selection bias can occur, both because of an incorrect study design and as a result of a low response rate. This study was designed to include all geriatric hospital units within one geographical area, and no selection on the basis of symptom prevalence in the units occurred. Also, the non-response rate was relatively low (18\%).

Another problem with a bearing on the validity of the study is response bias due to the awareness of exposure. Some building factors, such as building dampness, floor coating, and type of ventilation system, are known to the people who work in the buildings concerned. It is, thus, impossible to perform a blinded field study on such exposures. With regard to many of the measured exposures, however, the subjects had no previous information, and the results of the measurements were not reported to the units until the questionnaire investigation was completed. Also, only specific exposures and perceptions were related to each other. Misclassification of exposure is another possible source of bias in epidemiological studies. In our study, each subject was assigned the average exposure in the building, and we did not have personal exposure measurements. This could induce a misclassification, in buildings where the subjects have stationary workplaces, if there are large variations in the local climate within the buildings. Hospital employees, however, are very mobile and it is unlikely that misclassification of the exposure would have any significant influence on the results. With regard to the discussed aspects of internal validity, we do not think that the results of our study have been unduly affected by response bias, or selection bias. The cross sectional design, however, could entail an underestimation of the true effect of exposure related to buildings.

Most of the earlier studies on illness related to buildings have been performed in office workers. We have shown that symptoms compatible with the sick building syndrome are common in hospital workers, too. The most common symptoms were dry or red skin on the face, throat dryness, fatigue, feeling heavy headed, and eye irritation. The large variation in symptom prevalence between different hospital units supports the hypothesis that some symptoms are caused by exposures in the buildings. Similar observations were made in the large Danish Town Hall Study. ${ }^{5}$

The questionnaire used in our study was validated and is widely used by occupational health care units in Sweden. This questionnaire was also used in the large office illness project in the north of Sweden. ${ }^{4}$ When our results were compared with theirs, our female hospital workers turned out to have a higher prevalence of facial dermal symptoms, throat dryness, and eye irritation, than the female office workers in Sweden. ${ }^{4}$

In agreement with earlier studies, we showed that both personal factors and building related exposures influenced the prevalence of symptoms of SBS. We showed that smoking exerted a significant influence on general symptoms and throat symptoms, which agrees with earlier studies in office workers, ${ }^{16}$ school personnel, ${ }^{17}$ and hospital workers. ${ }^{18} \mathrm{We}$ also found that the prevalence of symptoms of SBS, particularly general symptoms and airway symptoms, was higher in subjects with asthma or hay fever. This is also in agreement with previous epidemiological investigations in office workers, ${ }^{716}$ and in the general population. ${ }^{3}$

Moreover, we showed that the psychosocial work climate had a strong influence on the prevalence of both general symptoms, eye symptoms, and facial skin symptoms. Similar results of general symptoms have been reported earlier in both offices, ${ }^{164}$ and in the general population, ${ }^{3}$ and a relation between facial skin symptoms, ${ }^{4}$ eye irritation, ${ }^{3}$ and a poor psychosocial climate has also been previously shown. Both eyes and facial skin contain trigeminal free nerve endings, which commonly sense chemical irritation. It has been shown experimentally that a poor psychosocial climate at work is related to a lower detection limit to trigeminal irritants. ${ }^{19}$ Thus, one possible explanation of our findings could be that subjects with a poor psychosocial climate are more susceptible to irritative indoor pollutants.

In our study, the indoor environment influenced the prevalence of symptoms of SBS, even when the influence of different personal factors was controlled. We found a relation between building age and both facial dermal symptoms and throat symptoms, and such symptoms were most common in new buildings. A similar relation of symptoms of SBS among office workers was found in the Danish Town Hall Study, ${ }^{5}$ and recently, dermal symptoms were found to be more common in subjects living in new dwellings. ${ }^{20}$

Weekly exposure to static electricity was reported in one third of the subjects, and was related to eye irritation and general symptoms, a finding that agrees with earlier studies. $^{321}$ The causal relation between reports on static electricity and eye symptoms is yet unclear, but one possible explanation could be the deposition of charged particles in the eyes.

All buildings in our study had mechanical ventilation, but there were covariations between building age, static electricity, air exchange rate, and ventilation noise, which limits our ability to distinguish between the effects of these exposures. Surprisingly, we found a significant relation between high exhaust air flow, and a high prevalence of eye irritation, throat symptoms, and facial skin symptoms. The symptom prevalence was highest in the newest building, the only unit where the average outdoor air flow exceeded the current standard of $8 \mathrm{1} / \mathrm{s} /$ person. $^{14}$ 
Recently, a large office study conducted in The Netherlands found a significant negative association between carbon dioxide $\left(\mathrm{CO}_{2}\right)$ concentration and symptoms of SBS. ${ }^{22}$ The authors concluded that this was due to the fact that $\mathrm{CO}_{2}$ concentrations were highest in the naturally ventilated buildings, which had the lowest complaint rates for other reasons. Furthermore, it has been shown that buildings with mechanical ventilation have a higher airborne concentration of endotoxins indoors than do naturally ventilated buildings, ${ }^{23}$ and a significant relation between the endotoxin concentration and symptoms of SBS was reported. ${ }^{23}$

The building with the highest rate of air exchange also had increased noise levels due to noise from the ventilation system. It is possible that this noise induced stress reaction could explain some symptoms. To our knowledge, no other studies have reported associations between ventilation noise and symptoms of SBS, but there are other studies that have reported increased symptoms at high ventilation flows. As recently proposed aetiological factors for SBS may differ from building to building, and in some larger buildings it is possible to perform a regression analysis within each building. ${ }^{24}$ Our buildings, however, were relatively small and the hospital workers were mobile and thus uniformly exposed.

In conclusion, new buildings do seem to entail exposures with adverse health effects that cannot be compensated for by a higher ventilation flow. Ventilation noise could be one side effect of increased ventilation, and should be minimised. Another possible side effect could be lower indoor air humidity at higher air exchange rates. In Scandinavia, relative air humidity indoors is low (10-30\%) during the winter. In 1990 we performed an experimental study in the two newest and best ventilated buildings from this study, and found that moderate steam humidification during the winter reduced the prevalence of throat symptoms, air dryness, and static electricity. ${ }^{25}$

Our study in hospitals supports earlier findings found in office workers. The results support the view that a multifactorial approach should be applied in the prevention of SBS. One way of minimising these symptoms is to ensure a sound psychosocial climate, and cut tobacco smoking to a minimum. To be able to build healthy buildings in the future, further research is needed to identify exposures in new buildings that cause annoyance reactions, or symptoms compatible with SBS.

This study was supported by grants from the National Swedish Council for Building Research and the County Council of Malmöhus.
1 Akimenko VV, Andersen I, Lebowitz $\mathrm{MD}$, Lindvall $\mathrm{T}$ The sick building syndrome. In: Berglund $\mathrm{B}$, Berglund U, Lindvall T, Sundell J, eds. Proceedings of Indoor Air 1984. Stockholm: Swedish Council for Building Research 1986;6:87-97.

2 Skov P, Valbjorn O, Pedersen BV, et al. Influence of indoor climate on the sick building syndrome in an office environment. Scand 7 Work Environ Health 1990;16: 363-71.

3 Norbäck D, Edling C. Environmental, occupational, and personal factors related to the prevalence of sick building syndrome in the general population. $\mathrm{Br} F$ Ind $\mathrm{Med}$ $1991 ; 48: 451-62$.

4 Stenberg B, Hansson Mild K, Sandström M, Sundell J, Wall S. A prevalence study of the sick building syndrome (SBS) and facial skin symptoms in office workers. Indoor Air 1993;3:71-81.

5 Skov $\mathrm{P}$, Valbjorn $\mathrm{O}$, et al. The sick building syndrome in the office environment: the Danish town hall study. Environment International 1987;13:339-49.

6 Burge S, Hedge A, Wilson S, Bass JH, Robertson A. Sick building syndrome: a study of 4373 office workers. Ann Occup Hyg 1987;48:493-504.

7 Jaakola JJK, Heinonen OP, Seppänen O. Sick building syndrome, sensation of dryness and thermal comfort in relation to room temperature in an office building: need for individual control of temperature. Environment International 1989;15:163-8.

8 Mölhave L, Bach B, Pedersen OF. Human reactions to low concentrations of volatile organic compounds. Environment International 1986;12:167-75.

9 Guteland G, Bernulf B. Statistical yearbook of Sweden 1993. Official statistics of Sweden, vol 79: statistics. Stockholm, Sweden: Statistics Sweden, 1992.

10 Wyon D. Sick buildings and the experimental approach Environmental Technology 1992;13:313-22.

11 Kelland P. Sick building syndrome, working environments and hospital staff. Indoor Environment 1992;1:335-40.

12 Andersson $\mathrm{K}$, Strid $\mathrm{G}$. The use of standardized questionnaires in building-related illness (BRI) and sick building syndrome (SBS) surveys. In: Levy F, Maroni M, eds. NATO/CCMS pilot study on indoor air quality, 4th Plenary Meeting. Oslo: National Institute of Occupational Health; 1992:47-64.

13 Gebski V, Leung O, McNeil D, Lunn D. SPIDA users manual, version 6. Eastwood, Australia: Statistical Computing Laboratory, 1992.

14 ASHRAE Standard 62-1989. Ventilation for acceptable indoor air quality. Atlanta: American Society of Heating, Refrigerating and Air-conditioning Engineers
Incorporated, 1989 .

15 National Swedish Institute of Occupational Safety and Health. Noise. Stockholm; 1992 AFS:10. (In Swedish.)

16 Skov P, Valbjorn O, et al. Influence of personal characteristics, job related factors and psychosocial factors on the sick building syndrome. Scand $₹$ Work Environ Health 1989;15:286-95.

17 Norbäck D, Torgen M, Edling C. Volatile organic compounds, respirable dust, and personal factors related to prevalence and incidence of sick building syndrome in primary schools. Br f Ind Med 1990;47:733-41.

18 Rogier C, Dabies F, Teissier R, Salamon R. Which role do smoking and air conditioning play in the occurrence of building sickness in hospital workers? Rev Epidemiol Sante Publique 1989;37:255-62.

19 Kjaergaard S, Pedersen OF, Molhave L. Sensitivity of the eyes to airborne irritant stimuli: influence of individual cyes to airborne irritant stimuli: influence of individu

20 Norbäck D, Edling C, Wieslander G. Sick building syndrome in the general Swedish population-the significance of outdoor and indoor air quality and seasonal variation. In: Jaakola JJK, Ilmarinen $\mathbf{R}$, Seppänen O, eds. Proceedings of Indoor Air ' 93 Vol 1 Health Effects. Helsinki: Laboratory of Heating, Ventilation, and Air Conditioning, 273-8.

21 Norbäck D, Michel I, Widström J. Indoor air quality and personal factors related to the sick building syndrome. Scand $\mathcal{F}$ Work Environ Health 1990;16:121-8

22 Zweers T, Preller L, Brunekreef B, Boleij JSM. Health and indoor climate complaints of 7043 office workers in 61 buildings in the Netherlands. Indoor Air 1992;2:127-36.

23 Teeuw B. Sick building syndrome, the role of airborne microorganisms and endotoxin. Utrecht: University of Utrecht, ganisms and endotoxin. Utrecht:

24 Harrison J, Pickering CAC, Faragher EB, Austwick PKC, Little SA, Lawton L. An investigation of the relationship between microbial and particulate indoor air pollution and the sick building syndrome. Respir Med 1992;86. 225-35.

25 Nordström K, Norbäck D, Akselsson R. Effect of air humidification on sick building syndrome and perceived indoor air quality in hospitals: a four month longitudinal study. Occup Environ Med 1994;51:683-8. 